\title{
Currency Integration under Labor Mobility : when Cost is incurred
}

Taiyo Yoshimi

Nanzan University, Aichi, Japan

\begin{abstract}
We assess whether renouncing monetary policy autonomy becomes a cost of currency integration under labor mobility in the framework of the New Open Economy Macroeconomics. Assuming Nash equilibrium among central banks of candidate countries, we find that the forfeiture of monetary policy autonomy becomes a cost when country-specific total factor productivity shocks hit them, labor input weights differ between candidate countries, and country specific shocks on marginal disutility of labor occur. These finer points suggest that it cannot generally be concluded that there is no cost of currency integration under labor mobility, as discussed in the classic Optimum Currency Area theory.
\end{abstract}

JEL Classifications: F30, F33, F41

Key words: : New Open Economy Macroeconomic (NOEM) Model, Currency Integration, Labor Mobility, Exchange Rate Regime

\footnotetext{
* Corresponding Author: Taiyo Yoshimi; Department of Economics, Nanzan University, 18 Yamazato-cho, Showa-ku, Nagoya, Aichi, 466-8673 Japan; Tel: +81 528323111, Fax: +81 528351444, E-mail: yoshimi@ic.nanzan-u.ac.jp.

Acknowledgements: I have benefited from discussions with and the comments of Shin-ichi Fukuda, Eiji Ogawa, and Tsutomu Watanabe. I would also like to thank the seminar participants at Hitotsubashi University, Nanzan University, and the Research Institute of Capital Formation, the Development Bank of Japan. All remaining errors are mine. This work was supported by the Japan Society for the Promotion of Science (JSPS), Grant-in-Aid for Young Scientists (B) (24730280).
} 


\section{Introduction}

This paper assesses the impact of currency integration on a region's member economies based on the New Open Economy Macroeconomics (NOEM) framework. Under currency integration, monetary policy management is the responsibility of common central bank in a unified zone. If the optimum monetary policy response is different for each country, or if member countries are hit by asymmetric shocks, forfeiture of autonomy over monetary policy becomes one of the costs of currency integration. For a long time, as part of the Optimum Currency Area (OCA) theory, there has been much debate on the scale of these costs and how they change depending on macroeconomic environments .

The OCA theory was pioneered by Mundell (1961), a seminal article. Since he first explored the conditions for OCAs, a consistent question in the literature has been, "Does a nation gain welfare when it forfeits its national currency and adopts a region-wide currency?" Mundell (1961)'s basic view on this point is that a nation loses welfare by forming a common currency when it lacks symmetry of shocks to other candidates or labor mobility. This view naturally encouraged empirical assessment on the existence of symmetry of shocks and labor mobility in the euro area and regions that people regard as future candidates for common currency zones. Bayoumi and Eichengreen (1993), in a pioneering work on the symmetry of shocks, concluded that the degree of symmetry of shocks in Europe was lower than that in the U.S. Following this work, many authors made efforts to extend this type of assessment to regions such as Europe and East Asia $^{2}$. Compared to the huge amount of work devoted to symmetry of shocks, empirical assessments on the degree of labor mobility are relatively limited because of the lack of data for migration between nations. Gáková and Dijkstra (2008) compared the U.S. and Europe in terms of labor mobility and concluded that the degree of labor mobility was higher in the U.S. than in Europe. Zimmermann (2009) suggested that barriers to labor mobility in Europe were difficult to lift and the degree of mobility was still insufficient to adjust unemployment in Europe.

Together with Mundell's seminal work, McKinnon (1963) and Kenen (1969) made pioneering contributions to this literature. McKinnon (1963) implied that the benefit

\footnotetext{
'De Grauwe (2012) excellently reviews the OCA literature.

2 See, for example, Fidrmuc and Korhonen (2003), Chow and Kim (2003), Kim and Chow (2003), Horvath and Rátfai (2004), and Zhang et al. (2004).
} 
of currency integration was positively linked to trade openness. Kollmann (2004) examined this view based on a Dynamic Stochastic General Equilibrium (DSGE) model and suggested that currency integration could significantly improve welfare by removing exchange-rate risks. He also suggested that this gain from the removal of those risks would become larger for a region with higher trade openness. As intraregional trade in Europe is larger than intra-national trade in the U.S., gains of currency integration in Europe are supposed to be larger than the implicit gains of having nationwide currency in the U.S. Kenen (1969) added several possible conditions for OCAs, such as fiscal coordination and symmetry of economic structures, that Mundell (1961) and McKinnon (1963) had not considered explicitly. Kenen (1969)'s work has great implications even for current policy debate, as the European Monetary Union (EMU) suffered greatly from the recent fiscal crises of Greece. Accordingly, fiscal cooperation is one of the EMU's ongoing discussions.

Given these three authors' seminal contributions, subsequent researchers tried to define OCAs from other points of view. Corden (1972) and Giersch (1973) suggested the importance of similarity of countries' preferences for inflation and unemployment rates. Given the stable relationship between the inflation and unemployment rates implied by the Phillips Curve, a policy authority has to decide upon a desirable combination of these two variables. Theoretically, currency integration is conducive to smooth inflation rates among member countries. Thus, if preferred combinations of inflation and unemployment rates differ across member countries, at least one country will always lose given the formation of a region-wide common currency. Accordingly, the similarity of these types of preferences can be a requirement to form an OCA.

Even when shocks themselves are symmetric, their effects on national economies vary across countries depending on their labor market institutions. Bruno and Sachs (1985) and Calmfors and Driffill (1988) suggested the importance of considering the difference in member countries' labor markets. Campolmi and Faia (2006) related the size of cyclical inflation differentials, observed for euro area countries, to the differences in labor market institutions across the same set of countries. They suggested that the difference in labor market institutions could explain the differences in inflation dynamics in euro area countries based on a DSGE model. Similarly, the difference in legal systems is supposed to generate a difference in responses to symmetric regionwide shocks. Dornbusch et al. (1998), Cecchetti (1999), Maclennan et al. (1999), Mojon (2000), and Peersman and Smets (2001) discussed this point and implied the importance of similarity in legal systems of candidate nations to form OCAs. 
Given the long history of the OCA literature, we will now revisit the seminal discussion on labor mobility by Mundell (1961). His classic OCA theory brought the cost of currency integration into question whilst simultaneously arguing that if free labor mobility is possible within an area, the impact of asymmetric shocks will be offset by the mobility of workers within the area and by wages. Based on this argument, it has been believed that free mobility of labor within an area being guaranteed is one key criterion for measuring the desirability of introducing a common currency. However, as Mundell's (1961) argument is rooted in the classic Keynesian system, it is not a conclusion obtained on the basis of microfoundations and explicit formulation of price rigidity. In this paper, we use the NOEM framework to review the classic OCA discussion regarding labor mobility. We also consider the heterogeneity of member nations, and examine whether there are differences between the integration of homogeneous and heterogeneous countries.

Research that discusses problems pertaining to OCAs based on microfoundations includes Bayoumi (1994), Dellas and Tavlas (2005), Corsetti (2008), and Ricci (2008). Especially, Corsetti's (2008) analysis is suggestive in the sense that he assumes the mobility of financial capital and the immobility of labor. In his model, households in member countries trade international bonds freely across borders. In this sense, financial capital is mobile and households in member countries can borrow from and lend to each other, sharing risks in relation to expected changes of consumption. It is interesting that the cost of currency integration arises even in this environment because of the existence of non-tradable goods and home biases in consumption baskets, although seminal papers such as Mundell (1961) and McKinnon (1963) refer to capital mobility as one possible condition for OCAs. This can be one of the clear advantages in reviewing the OCA criteria with strict general equilibrium models. The objective of this paper, in particular, is to review Mundell's (1961) theory on labor mobility. Research based on a similar awareness of the issues is presented by Bertola (1992). However, Bertola's (1992) framework does not assume price rigidity and does not contain suggestions regarding the OCA debate.

This paper is structured in the following manner. The following section presents the model that forms the basis of the analysis in this paper. Section III uses the model developed in Section II to examine the costs of currency integration. Section IV assumes heterogeneity between the two countries in question and conducts a re-analysis. Section $\mathrm{V}$ briefly discusses remaining issues and presents a conclusion. 


\section{Model}

In this model, there are two homogeneous countries: country $H$ and country $F$. Producers in each country specialize in producing a single tradable commodity. Goods produced in country $H$ are represented by $h$, and goods produced in country $F$ are represented by $f$; these goods are respectively distributed innumerably in $[0,1]$. The households of country $H$ and country $F$ are representedas $j$ and $j^{*}$, respectively, and are distributed innumerably in [0,1]. Moreover, in accordance with Erceg, Henderson and Levin (2000), as well as Obstfeld and Rogoff (2000), it is assumed that there is monopolistic competition in the goods and labor markets. The countries have a complete bond market, and households can trade international state-dependent bonds at zero cost. Each country's unique stochastic shocks occur in relation to household labor marginal disutility and corporate productivity.

\section{A. Consumer Behavior}

The expected present discounted value of the lifetime utility of household $j$ in country $H$ is defined as $u_{t}(j)$ in the following manner:

$$
u_{t}(j) \equiv E_{t} \sum_{\tau=t}^{\infty} \beta^{\tau-t}\left[\ln C_{\tau}(j)-\kappa_{\tau} l_{\tau}(j)\right]
$$

where $\beta<1$ represents the discount rate and $C_{t}(j)$ the consumption index. $l_{t}(j)$ is the labor supply index and is defined as $l_{t}(j) \equiv \int_{0}^{1} l_{t}(h, j) d h+\int_{0}^{1} l_{t}(f, j) d f$. Here, $l_{t}(h, j)$ and $l_{t}(f, j)$ respectively represent household $j$ 's labor input to company $h$ in country $H$ and company $f$ in country $F . \kappa_{t}$ represents stochastic shocks to labor disutility. For household $j$, the respective consumption indices for country $H$ 's goods and country $F$ 's goods are defined in the following manner:

$$
C_{H, t}(j) \equiv\left[\int_{0}^{1} C_{t}(h, j)^{\frac{\theta-1}{\theta}} d h\right]^{\frac{\theta}{\theta-1}}, \quad C_{F, t}(j) \equiv\left[\int_{0}^{1} C_{t}(f, j)^{\frac{\theta-1}{\theta}} d f\right]^{\frac{\theta}{\theta-1}}
$$

Here, $C_{t}(h, j)$ and $C_{t}(f, j)$ respectively represent the amount of goods $h$ and goods 
$f$ consumed by household $j$ during period $t$. $\theta$ denotes the elasticity of substitution between goods produced within the same country and has a value greater than one. The following is the total consumption index for household $j$, defined as a Cobb-Douglas type consumption index:

$$
C_{t}(j) \equiv C_{H, t}(j)^{\alpha} C_{F, t}(j)^{1-\alpha}
$$

Here, $\alpha$ represents the household consumption basket weight of country $H^{\prime}$ 's goods.

If $p_{t}(h)$ and $p_{t}(f)$ are the respective prices of goods $h$ and goods $f$ denominated in the currency of country $H$, the demand function of each of the goods can be sought from household cost minimization conditions in the following manner:

$$
C_{t}(h, j)=\left[\frac{p_{t}(h)}{P_{H, t}}\right]^{-\theta} C_{H, t}(j), \quad C_{t}(f, j)=\left[\frac{p_{t}(f)}{P_{F, t}}\right]^{-\theta} C_{F, t}(j)
$$

Further,

$$
C_{H, t}(j)=\alpha\left[\frac{P_{H, t}}{P_{t}}\right]^{-1} C_{t}(j), \quad C_{F, t}(j)=(1-\alpha)\left[\frac{P_{F, t}}{P_{t}}\right]^{-1} C_{t}(j)
$$

and here,

$$
\begin{gathered}
P_{t} \equiv \frac{P_{H, t}^{\alpha} P_{F, t}^{1-\alpha}}{\alpha_{w}} \text { where } \alpha_{w} \equiv \alpha^{\alpha}(1-\alpha)^{1-\alpha} \\
P_{H, t} \equiv\left[\int_{0}^{1} p_{t}(h)^{1-\theta} d h\right]^{\frac{1}{1-\theta}}, \quad P_{F, t} \equiv\left[\int_{0}^{1} p_{t}(f)^{1-\theta} d f\right]^{\frac{1}{1-\theta}}
\end{gathered}
$$

$P_{t}$ represents the Consumer Price Index (CPI) of country $H$, and $P_{H, t}$ and $P_{F, t}$ represent the Producer Price Index (PPI) and the import price index denominated in the currency of country $H$, respectively. Further, the budget constraint of household $j$ during period $t$ can be expressed in the following manner: 


$$
\begin{aligned}
\sum_{s_{t+1}} Q\left(s_{t+1} \mid s_{t}\right) B_{t}\left(s_{t+1}, j\right)+\varepsilon_{t} \sum_{s_{t+1}} Q^{*}\left(s_{t+1} \mid s_{t}\right) B_{t}^{*}\left(s_{t+1}, j\right) \\
\quad=B_{t-1}\left(s_{t}, j\right)+\varepsilon_{t} B_{t-1}^{*}\left(s_{t}, j\right)+\pi_{t}(j)+T_{t}(j)+\int_{0}^{1} w_{t}(h, j) l_{t}(h, j) d h \\
\quad+\int_{0}^{1} \varepsilon_{t} w_{t}^{*}(f, j) l_{t}(f, j) d f-\int_{0}^{1} p_{t}(h) C_{t}(h, j) d h \\
\quad-\int_{0}^{1} p_{t}(f) C_{t}(f, j) d f .
\end{aligned}
$$

$B_{t}\left(S_{t+1}, j\right)$ and $B_{t}^{*}\left(S_{t+1}, j\right)$ represent the state-dependent bond holdings when the state $S_{t+1}$ is realized in period $t+1 . Q\left(S_{t+1} \mid S_{t}\right)$ and $Q^{*}\left(S_{t+1} \mid S_{t}\right)$ represent the prices of these state-dependent bonds; the former are defined as being denominated in the currency of country $H$ and the latter in the currency of country $F . \varepsilon_{t}$ represents the nominal exchange rate denominated in the currency of country $H, \pi_{t}(j)$ represents the nominal dividend amount obtained from corporate shareholdings in country $H$, and $T_{t}(j)$ represents the lump-sum tax. $w_{t}(h, j)$ and $w_{t}^{*}(f, j)$ respectively represent the nominal wage that country $H$ household $j$ receives when employed at company $h$ or company $f . w_{t}(h, j)$ and $w_{t}^{*}(f, j)$ are defined as being denominated in the currency of country $H$ and country $F$, respectively.

Given the price of goods and the corporate labor demand function, households determine consumption $\left(C_{t}(j)\right)$, nominal wages $\left(w_{t}(h, j), w_{t}^{*}(f, j)\right)$, and bonds outstanding $\left(B_{t}\left(S_{t+1}, j\right), B_{t}^{*}\left(S_{t+1}, j\right)\right)$ in order to maximize utility under the budget constraint. The inter- and intra-temporal Euler equations can be obtained from household utility maximization conditions in the following manner:

$$
\beta E_{t}\left[\frac{P_{t} C_{t}(j)}{P_{t+1} C_{t+1}(j)}\right]=\frac{1}{1+i_{t+1}}, \quad w_{t}(h, j) \equiv \varepsilon_{t} w_{t}^{*}(f, j)=\frac{\phi}{\phi-1} \kappa_{t} P_{t} C_{t}(j)
$$

Here, $i_{t+1}$ represents the nominal interest rate. $\phi$ represents the elasticity of substitution between household labors in the same country and takes a value greater than one. The household variables for country $F$ are defined in the same manner as those for country $H$. Further, in this paper, because a complete bond market is assumed, the risk sharing condition $P_{t} C_{t}(j)=\varepsilon_{t} P_{t}^{*} C_{t}^{*}\left(j^{*}\right)$ is always established. 


\section{B. Producer Behavior}

The production technology of company $h$ conforms with the following production function:

$$
Y_{t}(h)=Z_{t} \tilde{l}_{t}(h) \quad \text { where } \tilde{l}_{t}(h) \equiv l_{H, t}(h)^{\delta} l_{F, t}(h)^{1-\delta}
$$

$Z_{t}$ represents the productivity shock to country $H$ companies. $\tilde{l}_{t}(h)$ represents the labor injection index of company $h . \delta$ represents the input basket weight of companies in both countries for country $H$ 's household labor. Further, $l_{H, t}(h)$ and $l_{F, t}(h)$ are the labor injection indices for company $h$ 's country $H$ and country $F$ household labor respectively; they are defined in the following manner:

$$
l_{H, t}(h) \equiv\left[\int_{0}^{1} l_{t}(h, j)^{\frac{\phi-1}{\phi}} d h\right]^{\frac{\phi}{\phi-1}}, \quad l_{F, t}(h) \equiv\left[\int_{0}^{1} l_{t}^{*}\left(h, j^{*}\right)^{\frac{\phi-1}{\phi}} d f\right]^{\frac{\phi}{\phi-1}}
$$

The respective indices for wages paid by company $h$ to household $j$ and household $j^{*}$ are defined in the following manner:

$$
W_{H, t} \equiv\left[\int_{0}^{1} w_{t}(h, j)^{1-\phi} d j\right]^{\frac{1}{1-\phi}}, \quad W_{F, t} \equiv\left[\int_{0}^{1} w_{t}\left(h, j^{*}\right)^{1-\phi} d j^{*}\right]^{\frac{1}{1-\phi}}
$$

The domestic nominal wage index for country $H$ is given in the following manner:

$$
W_{t} \equiv \frac{W_{H, t}^{\delta} W_{F, t}^{1-\delta}}{\delta_{w}} \quad \text { where } \delta_{w} \equiv \delta^{\delta}(1-\delta)^{1-\delta}
$$

\section{Pricing}

Companies determine product prices in order to maximize expected profits given consumers' demand function for goods and nominal wages. Nominal marginal cost and nominal wages have the following relationship:

$$
M C_{t}=Z_{t}^{-1} W_{t}
$$


Under rigid pricing, companies cannot immediately revise their prices in response to shocks that occur during the current term. In other words, pricing for period $t$ is done on the basis of information aggregation during period $t-1$, and optimal pricing behavior for company $h$ is expressed as $\max _{P t(h)} E_{t-1}\left[Q_{t-1, t} \Pi_{t}(h)\right]$. Here, $Q_{t-1, t}$ represents the stochastic discount factor and is defined as $Q_{t-1, t} \equiv \beta P_{t-1} C_{t-1} /\left[P_{t} C_{t}\right]$. Further, $\Pi_{t}(h)$ represents the profits of company $h$ and is given as

$$
\Pi_{t}(h) \equiv\left[p_{t}(h)-M C_{t}\right] \int_{0}^{1} C_{t}(h, j) d j+\left[\varepsilon_{t} p_{t}^{*}(f)-M C_{t}\right] \int_{0}^{1} C_{t}^{*}\left(h, j^{*}\right) d j^{*}
$$

$M C_{t}$ represents the nominal marginal costs of the companies in country $H$. Using first-order conditions allows prices in rigid price equilibrium assignment to be sought in the following manner:

$$
p_{t}(h)=P_{H, t}=\frac{\theta}{\theta-1} E_{t-1}\left[M C_{t}\right]=\zeta_{H} E_{t-1}\left[Z_{t}^{-1} K_{t} P_{t} C_{t}\right]
$$

where $\zeta_{H} \equiv \Phi^{-1} \delta_{w}^{-1}\left(\frac{1-\alpha}{\alpha}\right)^{1-\delta}, \quad \Phi \equiv \frac{\theta-1}{\theta} \frac{\phi-1}{\phi}$ and $K_{t} \equiv \delta_{w}^{-1} \kappa_{t}^{\delta} \kappa_{t}^{* 1-\delta}$

Here, $K_{t}$ represents the impact of shocks occurring in each country on nominal marginal costs for companies in country $H$ and country $F$.

In contrast, in a flexible price situation, the optimal pricing behavior for company $h$ is expressed as $\max _{P t(h)} \Pi_{t}(h)$. Using first-order conditions allows the price of goods $h$ under flexible pricing to be sought in the following manner:

$$
p_{t}^{f}(h)=P_{H, t}^{f}=\frac{\theta}{\theta-1} M C_{t}=\zeta_{H} Z_{t}^{-1} K_{t} P_{t} C_{t}
$$

Here, $p_{t}^{f}(h)$ represents the flexible price equilibrium level and $\mathrm{P}_{H, t}^{f}$ defines $\mathrm{P}_{H, t}^{f} \equiv$ $\left[\int_{0}^{1} p_{t}^{f}(h)^{1-\theta} d h\right]^{\frac{1}{1-\theta}}$ as the aggregate. Under a flexible price equilibrium, the price of goods $h$ is calculated as the value of a possible outcome of the nominal marginal cost, which includes the mark up percentage. Consequently, under flexible pricing, when shocks occur during the current term, the current term price can be immediately changed through changes to the possible outcome of the marginal cost for the current term. In this paper, we simply assume that the Law of One Price (LOOP) is achieved as 
follows;

$$
p_{t}^{*}(h)=\frac{\tilde{p}_{t}(h)}{\varepsilon_{t}}, \quad p_{t}(f)=\tilde{p}_{t}^{*}(f) \varepsilon_{t}
$$

Or

$$
\ln p_{t}^{*}(h)=\ln \tilde{p}_{t}(h)-\ln \varepsilon_{t}, \ln p_{t}(f)=\ln \tilde{p}_{t}^{*}(f)+\ln \varepsilon_{t}
$$

As a result of the company's profit maximization behavior, $p_{t}^{*}(h)$ the export price of country $H^{\prime} s$ company $h$ is determined in the following manner:

$$
p_{t}^{*}(h)=P_{H, t}^{*}=\frac{\theta}{\theta-1} \frac{1}{\varepsilon_{t}} E_{t-1}\left[M C_{t}\right]
$$

\section{Monetary Policy}

Monetary authorities decide on the course of nominal interest rates, both current and future, as part of their monetary policy stance. In this paper, following Corsetti and Pesenti (2005), the monetary policy stance of country $H$ is defined as $\mu_{t}$, and it satisfies the following relationship:

$$
\frac{1}{\mu_{t}}=\beta\left(1+i_{t+1}\right) E_{t}\left[\frac{1}{\mu_{t+1}}\right]=E_{t} \lim _{N \rightarrow \infty} \beta^{N} \frac{1}{\mu_{t+N}} \prod_{\tau=0}^{N-1}\left(1+i_{t+\tau+1}\right)
$$

A rise in $\mu_{t}$ implies monetary easing; a fall in $\mu_{t}$ implies monetary tightening. As is evident from this, $\mu_{t}$ rises when either the current interest rate or the expected value of the future interest rate falls. If it is expected that the interest rate will fall in the future, households will immediately begin adjusting, and it can be envisaged that people would begin withdrawing their deposits. Consequently, this implies both manipulation of the current interest rate and monetary policy that impacts future interest rate expectations.

In order to avoid complicating the following description $j, j^{*}, h$, and $f$ have been omitted and each variable is expressed as a macro unit. In Table 1, all the endogenous variables in the model developed thus far are represented as stochastic shocks $\left(Z_{t}, Z_{t}^{*}\right.$, 
$\kappa_{t}$ and $\left.\kappa_{t}^{*}\right)$ and the monetary policy stances of country $H$ and country $F\left(\mu_{t}, \mu_{t}^{*}\right)$ are also presented. In Table $1, \zeta_{F}$ is defined in the following manner:

$$
\zeta_{F} \equiv \Phi^{-1} \delta_{w}^{-1}\left(\frac{\alpha}{1-\alpha}\right)^{\delta}
$$

\section{Monetary Policy and Integration Costs}

\section{A. Optimal Monetary Policy}

In this paper, we derive the public welfare losses that occur in the following three regimes: a Nash regime, a cooperative regime, and a currency union regime; we examine whether a currency union regime creates additional losses compared to the other two regimes. In a Nash regime, each country's monetary authorities decide on a monetary policy stance in order to minimize their country's public welfare losses. Consequently, this regime can be regarded as a case that corresponds with a general open economic model assuming a complete floating-rate system. In contrast, in a cooperative regime, each country's monetary authorities decide their own monetary policy stances in order to minimize the sum of both countries' public welfare losses. In a currency union regime, the countries' monetary policy stance is unified, so the common central bank decides on a unified monetary policy stance in order to minimize the sum of both countries' public welfare losses. 


\section{Table 1. List of Equations}

$$
\begin{aligned}
& M C_{t}=\frac{\theta-1}{\theta} \zeta_{H} Z_{t}^{-1} K_{t} \mu_{t}, \quad M C_{t}^{*}=\frac{\theta-1}{\theta} \zeta_{F} Z_{t}^{*-1} K_{t} \mu_{t}^{*}, \\
& P_{H, t}=\zeta_{H} E_{t-1}\left[Z_{t}^{-1} K_{t} P_{t} C_{t}\right], \quad P_{F, t}^{*}=\zeta_{F} E_{t-1}\left[Z_{t}^{*-1} K_{t} P_{t}^{*} C_{t}^{*}\right], \\
& P_{H, t}^{*}=\zeta_{H} \varepsilon_{t}^{-1} E_{t-1}\left[Z_{t}^{-1} K_{t} P_{t} C_{t}\right], \quad P_{F, t}=\zeta_{F} \varepsilon_{t} E_{t-1}\left[Z_{t}^{*-1} K_{t} P_{t}^{*} C_{t}^{*}\right], \\
& C_{t}=\mu_{t} \alpha_{w} \frac{\theta-1}{\theta} \frac{1}{\left(E_{t-1}\left[M C_{t}\right]\right)^{\alpha}\left(\varepsilon_{t} E_{t-1}\left[M C_{t}^{*}\right]\right)^{1-\alpha}}, \\
& C_{t}^{*}=\mu_{t}^{*} \alpha_{w} \frac{\theta-1}{\theta} \frac{1}{\left(\varepsilon_{t}^{-1} E_{t-1}\left[M C_{t}\right]\right)^{\alpha}\left(E_{t-1}\left[M C_{t}^{*}\right]\right)^{1-\alpha}}, \\
& \tilde{l}_{t}=\frac{1}{\zeta_{H}} \frac{Z_{t}^{-1} P_{t} C_{t}}{E_{t-1}\left[Z_{t}^{-1} K_{t} P_{t} C_{t}\right]}, \quad \tilde{l}_{t}^{*}=\frac{1}{\zeta_{F}} \frac{Z_{t}^{*-1} P_{t}^{*} C_{t}^{*}}{E_{t-1}\left[Z_{t}^{*-1} K_{t} P_{t}^{*} C_{t}^{*}\right]}, \\
& l_{t}=\frac{\delta K_{t}}{\kappa_{t}}\left(\tilde{l}_{t}+\tilde{l}_{t}^{*}\right), l_{t}^{*}=\frac{(1-\delta) K_{t}}{\kappa_{t}^{*}}\left(\tilde{l}_{t}+\tilde{l}_{t}^{*}\right), \varepsilon_{t}=\frac{1-\alpha}{\alpha} \frac{\mu_{t}}{\mu_{t}^{*}}
\end{aligned}
$$

However, monetary authorities shall implement monetary policies that are accompanied by commitments. In this paper, monetary neutrality is set so that monetary policy does not have any sort of impact on the flexible price equilibrium assignment. Thus, the divergence from economic welfare $U_{t}^{f}$ based on the flexible price of economic welfare $U_{t}$ of a rigid price equilibrium assignment obtained using the expected value is defined as loss function $L_{t}$, that is $\left(L_{t} \equiv E_{t-1}\left[U_{t}^{f}-U_{t}\right]\right)$. $U_{t}$ is the consumer utility function as seen on a single country level or per capita level and is defined as $U_{t} \equiv E_{t} \sum_{\tau=t}^{\infty} \beta^{\tau-t}\left[\ln C_{t}\right.$ $\left.-\kappa_{t} l_{t}\right]$. Similarly, the objective function of the monetary authority of country $F$ is also expressed as $L_{t}^{*}$. Thus, $L_{t}$ and $L_{t}^{*}$ are obtained in the following manner:

$$
L_{t}=L_{t}^{*}=E_{t-1}\left[\alpha \ln \left(\frac{E_{t-1}\left[Z_{t}^{-1} K_{t} \mu_{t}\right]}{Z_{t}^{-1} K_{t} \mu_{t}}\right)+(1-\alpha) \ln \left(\frac{E_{t-1}\left[Z_{t}^{*-1} K_{t} \mu_{t}^{*}\right]}{Z_{t}^{*-1} K_{t} \mu_{t}^{*}}\right)\right]
$$

Thus, each country's monetary authorities can avoid the occurrence of public welfare losses that accompany price rigidity by curbing the impact of unforeseen 
shocks to a foreseen level. ${ }^{3}$ Thus, the optimizing behavior of each country's monetary authorities is represented as $\min _{\mu_{t}} L_{t}, \min _{\mu_{t}^{*}} L_{t}^{*}$, in a Nash regime, as $\min _{\mu_{t}}\left[L_{t}+L_{t}^{*}\right]$, $\min _{\mu_{t}^{*}}\left[L_{t}+L_{t}^{*}\right]$ in a cooperative regime, and as $\left.\min _{\mu_{t}}\left[L_{t}+L_{t}^{*}\right]\right|_{\mu_{t}^{*}=\mu_{t}}$ in a currency union regime.

\section{B. Costs of Currency Integration}

Here, we assess the costs of currency integration. The results of analysis in this paper are summarized in Table 2. The optimal monetary policy rules for each country under a Nash regime can be derived from the optimizing behavior of monetary authorities in the following manner:

\section{Table 2. Welfare Loss under Carrency Integration}

(relative to floating system)

\begin{tabular}{|c|c|c|c|}
\hline & $\begin{array}{c}\text { (i) homogenous } \\
\text { consumption basket } \\
\text { and labor input basket } \\
\alpha=\alpha^{*} \& \delta=\delta^{*}\end{array}$ & $\begin{array}{c}\text { (ii) heterogenous } \\
\text { consumption basket } \\
\alpha \neq \alpha^{*} \& \delta=\delta^{*}\end{array}$ & $\begin{array}{c}\text { (iii) heterogenous } \\
\text { labor input basket } \\
\alpha=\alpha^{*} \& \delta \neq \delta^{*}\end{array}$ \\
\hline $\begin{array}{c}\text { (a) Asymmetry of } \\
\text { TFP shocks } \\
Z \neq Z^{*} \& \kappa=\kappa^{*}\end{array}$ & $\begin{array}{c}\text { greater public } \\
\text { welfare loss }\end{array}$ & $\begin{array}{c}\text { greater public } \\
\text { welfare loss }\end{array}$ & $\begin{array}{c}\text { greater public } \\
\text { welfare loss }\end{array}$ \\
\hline $\begin{array}{c}\text { (b) Asymmetry of labor } \\
\text { marginal disutilitry } \\
\text { shocks }\end{array}$ & same welfare loss & same welfare loss & $\begin{array}{c}\text { greater public } \\
\text { welfare loss }\end{array}$ \\
\begin{tabular}{c}
$Z=Z^{*} \& \kappa \neq \kappa^{*}$ \\
\hline
\end{tabular} & & & \\
\hline
\end{tabular}

(Notes) (i), (ii), and (iii) represent a case with two homogeneous countries, a case with heterogeneity in the consumption basket and a case with heterogeneity in the labor input basket, respectively. Further, (a) and (b) respectively represent the results of analyses when asymmetry of TFP shocks and labor marginal disutility

$$
\begin{aligned}
& { }^{3} \text { The loss function can be rewritten using marginal cost and price levels in the following manner: } \\
& L_{t}=E_{t-1}\left[\alpha \ln \left(\frac{P_{H, t}}{P_{H, t}^{f}}\right)+(1-\alpha) \ln \left(\frac{P_{F, t}}{P_{F, t}^{f}}\right)\right]=E_{t-1}\left[\alpha \ln \left(\frac{E_{t-1}\left[M C_{t}\right]}{M C_{t}}\right)+(1-\alpha) \ln \left(\frac{E_{t-1}\left[M C_{t}^{*}\right]}{M C_{t}^{*}}\right)\right] \\
& L_{t}^{*}=E_{t-1}\left[\alpha \ln \left(\frac{P_{H, t}^{*}}{P_{H, t}^{* t}}\right)+(1-\alpha) \ln \left(\frac{P_{F, t}^{*}}{P_{F, t}^{* f}}\right)\right]=E_{t-1}\left[\alpha \ln \left(\frac{E_{t-1}\left[M C_{t}\right]}{M C_{t}}\right)+(1-\alpha) \ln \left(\frac{E_{t-1}\left[M C_{t}^{*}\right]}{M C_{t}^{*}}\right)\right]
\end{aligned}
$$

Thus, it is evident that by curbing the impact of unforeseen shocks to a foreseen level and eliminating public welfare losses, the divergence from the expected value for marginal cost can be curbed at zero, or that this corresponds with adjusting the domestic price level under rigid prices to a level below flexible prices. 
shocks are assumed.

$$
1=\frac{Z_{t}^{-1} K_{t} \mu_{t}^{\text {Nash }}}{E_{t-1}\left[Z_{t}^{-1} K_{t} \mu_{t}^{\text {Nash }}\right]}, \quad 1=\frac{Z_{t}^{*-1} K_{t} \mu_{t}^{* N a s h}}{E_{t-1}\left[Z_{t}^{*-1} K_{t} \mu_{t}^{* N a s h}\right]}
$$

Here, $\mu_{t}^{\text {Nash }}$ and $\mu_{t}^{* \text { Nash }}$ represent the optimal monetary policy stances for country $H$ and country $F$, respectively in a Nash regime. Similarly, superscripts Coop and $C U$ represent cooperative and currency union regimes, respectively. As mentioned earlier, these optimal monetary policy rules indicate that the optimal behavior for monetary authorities is to curb the impact of unforeseen shocks to an expected value level. If marginal cost is used, these rules can be re-written in the following manner:

$$
1=\frac{M C_{t}}{E_{t-1}\left[M C_{t}\right]}, \quad 1=\frac{M C_{t}^{*}}{E_{t-1}\left[M C_{t}^{*}\right]}
$$

Consequently, this implies that the optimal monetary policy response in a Nash regime is to curb only the country's own marginal cost to the expected level. Based on these rules, public welfare losses take a value of zero. This is attributable to the fact that when fluctuations occur in the nominal exchange rate, import price fluctuations under flexible prices match that of import price fluctuations under the rigid price equilibrium. For example, if the monetary authority of country $H$ aims to stabilize the national marginal cost, it can adjust so that $P_{H, t}$ matches $P_{H, t}^{f}$. While exchange rate fluctuations occur in line with this, if import prices under rigid price equilibrium $P_{F, t}$ do not deviate from flexible price equilibrium $P_{F, t}^{f}$, this does not cause public welfare losses. The same argument applies for country $F$.

An interesting and important examination is to consider the case of the Stackelberg regime, as the relationship between national central banks might have had leaderfollower characteristics in Europe during the European Moretary System period, from 1979 to 1998. At that time, central banks in the region were supposed to follow the Bundesbank's monetary policy in order to realize convergence of their home inflation rates to the lowest rate of inflation in Germany. Thus, examining the Stackelberg regime seems to be suggestive of a realistic policy debate in line with forming a common currency zone. As far as we take our current structure of the model as given, Nash and Stackelberg equilibriums are indifferent. Stackelberg equilibrium is defined as an equilibrium in which the leader makes a decision knowing the follower's reaction 
function to a leader's decision. As given by Equation (25), the optimal monetary policy stances of both central banks can be derived as functions of shocks and future expectations of their own stances. This implies that the central bank in one country does not care about the monetary policy stance in another country in an optimal response. In other words, the optimal monetary policy stance is not a function of the other member's policy stance, but focuses on exogenous shocks. Thus, Nash and Stackelberg equilibriums become indifferent in our model.

Optimal monetary policy rules can also be derived in the same manner for a cooperative regime as follows:

$$
1=\frac{Z_{t}^{-1} K_{t} \mu_{t}^{\text {Coop }}}{E_{t-1}\left[Z_{t}^{-1} K_{t} \mu_{t}^{\text {Coop }}\right]}, \quad 1=\frac{Z_{t}^{*-1} K_{t} \mu_{t}^{* \text { Coop }}}{E_{t-1}\left[Z_{t}^{*-1} K_{t} \mu_{t}^{* \text { Coop }}\right]}
$$

Consequently, it is evident that the optimal monetary policy rules for a cooperative regime match those in the case of a Nash regime. This intuitive understanding can be described in the following manner. We assumed the law of one price regardless of whether there is price rigidity. Consequently, exchange rate fluctuations accompanying the invoking of monetary policy do not lead to disconnection of rigid price equilibrium levels and flexible price equilibrium levels, namely public welfare losses. Invoking the country's own monetary policy has an impact on the selling prices of goods through (1) fluctuations in the country's nominal marginal cost and (2) fluctuations in the import price levels that accompany exchange rate fluctuations. In particular, when these unforeseen fluctuations in selling prices occur, there is an impact on public welfare. However, as described thus far, the fluctuations in nominal exchange rates (2) do not cause public welfare losses. In other words, even in a cooperative regime, in which the country's own monetary authorities take into consideration the prices of the country's own goods denominated in the foreign currency, the duty of the country's own monetary authority is to curb unforeseen fluctuations in the country's own nominal marginal cost. Consequently, the optimal monetary policy rules in a Nash regime and a cooperative regime match; moreover, in either case, public welfare losses can be curbed at zero.

In contrast, the optimal monetary policy stance of the common central bank in a currency union regime is obtained in the following manner: 


$$
\begin{array}{r}
1=\alpha \frac{Z_{t}^{-1} K_{t} \mu_{t}^{C U}}{E_{t-1}\left[Z_{t}^{-1} K_{t} \mu_{t}^{C U}\right]}+(1-\alpha) \frac{Z_{t}^{*-1} K_{t} \mu_{t}^{C U}}{E_{t-1}\left[Z_{t}^{*-1} K_{t} \mu_{t}^{C U}\right]} \\
=\alpha \frac{M C_{t}}{E_{t-1}\left[M C_{t}\right]}+(1-\alpha) \frac{M C_{t}^{*}}{E_{t-1}\left[M C_{t}^{*}\right]} .
\end{array}
$$

For example, the common central bank adopts a monetary policy stance that is only aimed at stabilizing country $H$ 's marginal cost. At this time, although the prices of country $H$ 's goods $P_{H, t}$ and $P_{H, t}^{*}$ within both countries are regulated by the flexible price equilibrium level, by diverging from the expected value level, country $F$ 's marginal cost $M C_{t}^{*}$ indicates that the prices of country $F^{\prime}$ 's goods $P_{F, t}$ and $P_{F, t}^{*}$ end up diverging from the flexible price level. In this case, there will be large public welfare losses in both countries. The common central bank will minimize the sum of the countries' public welfare losses; thus, such a policy decision is not the optimal choice. As a result, the optimal choice is for the common central bank to aim to stabilize each country's marginal cost as well as the price of each country's goods according to the household consumption basket weight.

Now, by way of experiment, we focus only on the asymmetry of productivity shocks $\left(Z_{t} \neq Z_{t}^{*}, \kappa_{t}=\kappa_{t}^{*}\right)$. Although in a Nash regime or a cooperative regime public welfare losses can be curbed at zero, it is evident that in a currency union regime, generally positive public welfare losses will occur. This is because, as evident from the other two regimes, it is necessary for the monetary authorities of each country to adopt a different monetary policy stance in order to curb public welfare losses at zero. Consequently, in a currency union regime, where there is no room for both countries to adopt different monetary policy stances, there will always be positive public welfare losses. This indicates that if asymmetric productivity shocks were assumed, even between two countries where free labor mobility is possible, costs of currency integration would arise.

Next, we focus only on the asymmetry of labor disutility shocks $\left(Z_{t}=Z_{t}^{*}, \kappa_{t} \neq \kappa_{t}^{*}\right)$. In this case, it is evident that it is possible to curb public welfare losses at zero even in a currency union regime, and integration costs do not arise. This is because in all exchange rate policy regimes, optimal monetary policy responses curb divergence from the expected value $K_{t}$. In other words, irrespective of whether there are currency integration constraints, since optimal monetary policy responses are equivalent, being constrained is not in itself the reason that causes some sort of additional public welfare loss to 
occur. This is attributable to the fact that because companies in both countries employ households in both countries, asymmetric labor disutility shocks have a symmetrical impact on the marginal cost of each country. If only labor disutility shocks are assumed, each country's respective marginal cost can be expressed in the following manner:

$$
M C_{t}=\frac{\theta-1}{\theta} \zeta_{H} K_{t} \mu_{t}, \quad M C_{t}^{*}=\frac{\theta-1}{\theta} \zeta_{F} K_{t} \mu_{t}^{*}
$$

Consequently, fluctuations in each country's marginal cost that accompany labor disutility shocks are both shared as $K_{t}$, and because the marginal cost is regulated at the expected value level, it is not necessary for each country's monetary authorities to adopt different policy responses.

In this paper, the results of the analysis are dependent on the type of shock for the following reasons. While productivity shocks only cause direct fluctuation in the country's own marginal cost, in an environment where there is labor mobility, labor productivity shocks that occur in one country simultaneously cause fluctuations in both countries' marginal costs. Consequently, the repercussions for the loss function of the impact of the shock will differ depending on the type of shock. This implies that the results of the analysis also differ depending on the type of the shock.

\section{Heterogeneity and Integration Cost}

In this section, we conduct a review of two heterogeneities that have an important impact on the results of our analysis. Firstly, by re-defining the consumption index of each country's households in the following manner, we take into consideration the heterogeneity of the consumption basket.

$$
C_{t}(j) \equiv C_{H, t}(j)^{\alpha} C_{F, t}(j)^{1-\alpha}, \quad C_{t}^{*}\left(j^{*}\right) \equiv C_{H, t}\left(j^{*}\right)^{\alpha^{*}} C_{F, t}\left(j^{*}\right)^{1-\alpha^{*}}
$$

At this time, the existence of asymmetrical productivity shocks generates currency integration costs. ${ }^{4}$ However, this conclusion is the same as in the case of two

\footnotetext{
${ }^{4}$ If heterogeneity of the consumption basket is assumed, the optimal monetary policy rules can be derived in the following manner: $1=\frac{z_{t}^{-1} K_{t} \mu_{t}^{N a s h}}{E_{t-1}\left[Z_{t}^{-1} K_{t} \mu_{t}^{N a s h}\right]}, \quad 1=\frac{Z_{t}^{*-1} K_{t} \mu_{t}^{* N a s h}}{E_{t-1}\left[Z_{t}^{*-1} K_{t} \mu_{t}^{* N a s h}\right]^{\prime}} \quad 1=\frac{\alpha+\alpha^{*}}{2} \frac{Z_{t}^{-1} K_{t} \mu_{t}^{C U}}{E_{t-1}\left[Z_{t}^{-1} K_{t} \mu_{t}^{C U}\right]}+\frac{2-\alpha-\alpha^{*}}{2} \frac{Z_{t}^{*-1} K_{t} \mu_{t}^{* C U}}{E_{t-1}\left[Z_{t}^{*-1} K_{t} \mu_{t}^{* C U}\right]}$
} 
homogenous countries and is not attributable to heterogeneity of the consumption basket. As mentioned earlier, the optimal behavior of each country's monetary authorities is only to respond to unforeseen fluctuations in their own country's marginal cost. This result is also achieved even if we consider heterogeneity of the consumption basket. Consequently, even in this case, the complete elimination of public welfare losses is not achieved in a currency union regime; moreover, compared with the Nash and cooperative regimes, additional public welfare losses occur.

Next, we conduct a review of the heterogeneity of companies' labor input baskets by assuming the following production functions for each country:

$$
Y_{t}(h) \equiv Z_{t} n_{H, t}(h)^{\delta} n_{F, t}(h)^{1-\delta}, \quad Y_{t}^{*}(f) \equiv Z_{t}^{*} n_{H, t}^{*}(f)^{\delta^{*}} n_{F, t}^{*}(f)^{1-\delta^{*}}
$$

As is assumed from the discussion thus far, the conclusion regarding labor disutility shocks is greatly altered when heterogeneity exists in companies' labor input baskets. ${ }^{5}$ The discussion regarding asymmetrical productivity shocks basically does not change from that of the homogenous case. Both asymmetrical productivity shocks and labor disutility shocks cause currency integration costs. In the case of two homogenous countries, the reason that the existence of labor disutility shocks did not lead to currency integration costs is that the companies in the countries had a common labor input basket; the impact that labor disutility shocks that occurred in each country had on each country's marginal cost was $K_{t}$ and were equivalent. Consequently, if heterogeneity exists in the labor input basket as assumed here, the impact that labor disutility shocks have on each country's marginal cost will diverge, and it will become necessary for each country's monetary authorities to achieve stabilization of their own country's marginal cost using different policy responses. Consequently, a currency union regime, which eliminates such monetary policy management autonomy, will produce public welfare costs.

\footnotetext{
${ }^{5}$ If heterogeneity of the labor input basket is assumed, the optimal monetary policy rules can be derived in the following manner: $1=\frac{z_{t}^{-1} K_{t} \mu_{t}^{N a s h}}{E_{t-1}\left[Z_{t}^{-1} K_{t} \mu_{t}^{N a s h}\right]}, \quad 1=\frac{z_{t}^{*-1} K_{t}^{*} \mu_{t}^{* N a s h}}{E_{t-1}\left[Z_{t}^{*-1} K_{t}^{*} \mu_{t}^{* N a s h}\right]}, \quad 1=\alpha \frac{z_{t}^{-1} K_{t} \mu_{t}^{C U}}{E_{t-1}\left[Z_{t}^{-1} K_{t} \mu_{t}^{C U}\right]}+(1-\alpha) \frac{z_{t}^{*-1} K_{t}^{*} \mu_{t}^{C U}}{E_{t-1}\left[z_{t}^{*-1} K_{t}^{*} \mu_{t}^{C U}\right]}$ Here, $K_{t}^{*} \equiv \frac{\left(\kappa_{t}\right)^{\delta^{*}}\left(\kappa_{t}^{*}\right)^{1-\delta^{*}}}{\left(\delta^{*}\right)^{\delta^{*}}\left(1-\delta^{*}\right)^{1-\delta^{*}}}$.
} 


\section{Conclusion}

This paper used the NOEM framework to review a classic OCA theory: that forfeiture of monetary policy autonomy does not become a cost of currency integration in areas where there is free labor mobility. The conclusion can be summarized in the following manner. If there is asymmetry in total factor productivity (TFP) shocks, currency integration costs will always arise. Further, if there is asymmetry in labor disutility shocks, costs will arise when there is heterogeneity in labor input baskets.

The characteristic feature of the model presented in this paper is the following: assuming labor mobility between two countries, labor disutility shocks that occur in one country will produce fluctuations in the marginal costs of the other country, thereby impacting currency integration costs. On this basis, this paper draws the conclusion that currency integration costs may arise even where free movement of labor is possible, which is a different conclusion from that of Mundell (1961). However, it is necessary to bear in mind the fact that the model in this paper assumes monopolistic competition in the labor market and incomplete substitution of labor between two countries, and it does not necessarily directly negate Mundell's (1961) conclusion. Moreover, in Corsetti's (2008) analysis, which does not assume labor mobility, although it is pointed out that consumption basket convergence is one of the prerequisites for an OCA, the results of the analysis in this paper suggest that even when there is consumption basket convergence, costs may arise.

Although measures and policies pursued in areas such as Europe have historically tried to realize flexible labor mobility, we suggest that the costs will arise when there is heterogeneity in the consumption basket. Additionally, it is evident that costs also arise when companies have a bias in labor input. Consequently, even when attempting to alleviate differences in the timing of business cycles within a common currency zone by liberalizing labor mobility, we need to consider whether companies on the labor demand side are prepared to accept labor from other countries without bias, or whether the environment is one in which consumers' consumption baskets converge and in which the impact of shocks that occur in each country and price fluctuations in their own country's goods impact consumers equally.

Finally, this paper leaves two broad issues for future consideration. The first is the issue of empirical measurement of costs. As is evident from the analysis in this paper, as long as the macro shocks between the two countries are symmetrical, $\left(Z_{t}=Z_{t}^{*}\right.$ as 
well as $K_{t}=K_{t}^{*}$ ), no currency integration costs will arise at all. Consequently, directly measuring the symmetry of shocks is one method that could be used to measure the scale of costs. Research based on such a perspective has been conducted since the work of Bayoumi and Eichengreen (1993), and comparatively recent studies that can be cited are Horvath and Rátfai (2004) and Frenkel and Nickel (2005). Analyses such as these are also important from the perspective of empirical measurement of costs. Related to this point, obtaining quantitative implications of labor mobility can be helpful for the policy debate. Although we have assumed free mobility of workers in this research, the degree of mobility will vary across pairs of countries. This variety might affect qualitative implications of our discussion in this paper.

The second issue that could be addressed in future research is how to evaluate the beneficial aspects of eliminating exchange rate uncertainty brought about by currency integration. The analysis in this paper only focuses on the cost side of forfeiting monetary policy autonomy and does not consider the beneficial aspects. This becomes a rather important aspect when considering actual policy decisions. For example, Kollmann (2004) and Dellas and Tavlas (2005) used the dynamic general equilibrium model framework and indicated that these benefits are significant in scale. In order to bring the analysis in this paper closer to policy debate, comparison with beneficial aspects is also important.

Received 09 March 2013, Revised 09 November 2013, Accepted 15 December 2013

\section{References}

Bayoumi, T. (1994) “A formal model of optimum currency areas,” IMF Staff Papers, Vol.41, No.4.

Bayoumi, T., and Eichengreen, B. (1993) "Shocking aspects of European monetary integration," In: Adjustment and Growth in the European Monetary Union, ed. by F. Torres, and F. Giavazzi, Cambridge University Press.

Bertola, G. (1992) "Models of economic integration and localized growth,” CEPR Discussion Paper, No. 651.

Bruno, M. and Sachs, J. D. (1985) Economics of Worldwide Stagflation, Harvard University Press.

Calmfors, L. and Driffill, J. (1988) "Bargaining structure, corporatism and macroeconomic performance," Economic Policy, 3(6), 13-61.

Campolmi, A. and Faia, E. (2006) "Cyclical inflation divergence and different labor market institutions in the EMU,” ECB Working Paper Series, No. 619.

Cecchetti, S. G. (1999) "Legal structure, financial structure, and the monetary policy transmission mechanism," NBER Working Paper Series, No. 7151. 
Chow, H. K. and Kim, Y. (2003) "A common currency peg in East Asia? Perspectives from Western Europe," Journal of Macroeconomics, 25(3), 331-350.

Corden, W. M. (1972) “Monetary integration,” Essays in International Finance, No.93, Princeton University.

Corsetti, G. (2008) "A modern reconsideration of the theory of optimal currency areas," CEPR Discussion Papers, No. 6712.

Corsetti, G. and Pesenti, P. (2005) "International dimensions of optimal monetary policy," Journal of Monetary Economics, 52(2), 281-305.

De Grauwe, P. (2012) Economics of Monetary Union 9th Edition, Oxford University Press.

Dellas, H. and Tavlas, G. (2005) “Wage rigidity and monetary union," Economic Journal, 115, 907-927.

Dornbusch, R., Favero, C. A. and Giavazzi, F. (1998) "Immediate challenges for the European Central Bank," Economic Policy, 26, 15-64.

Erceg, C. J., Henderson D. W. and Levin, A. T. (2000) "Optimal monetary policy with staggered wage and price contracts," Journal of Monetary Economics, 46, 281-313.

Fidrmuc, J. and Korhonen, I. (2003) "Similarity of supply and demand shocks between the euro area and the CEECs," Economic Systems, 27, 313-334.

Frenkel, M. and Nickel, C. (2005) "New European Union members on their way to adopting the Euro: an analysis of macroeconomic disturbances," Global Finance Journal, 15, 303-320.

Gáková, Z. and Dijkstra, L. (2008) "Labour mobility between the regions of the EU-27 and a comparison with the USA," Regional Focus, No.02/2008, European Union.

Giersch, H. (1973) "On the desirable degree of flexibility of exchange rates," Weltwirtschaftliches Archiv, 109, 191-213.

Horvath, J. and Rátfai, A. (2004) "Supply and demand shocks in accession countries to the Economic and Monetary Union," Journal of Comparative Economics, 32, 202-211.

Kenen, R. (1969) "The theory of optimum currency areas: an eclectic view," In: Monetary Problems of the International Economy, ed. by R. Mundell and A. Swoboda, University of Chicago Press.

Kim, Y. and Chow, H. K. (2003) "Optimum currency area in Europe: an alternative assessment," Economic Letters, 81, 297-304.

Kollmann, R. (2004) "Welfare effects of a monetary union: the role of trade openness," Journal of the European Economic Association, 2, 289-301.

Maclennan, D., Muellbauer, J. and Stephens, M. (1999) "Asymmetries in housing and financial market institutions and EMU," CEPR Discussion Papers, No. 2062.

McKinnon, R. I. (1963) “Optimum Currency Areas,” The American Economic Review, 53, 717-725.

Mundell, R. A. (1961) “The theory of optimum currency areas,” The American Economic Review, 51, 657-665.

Mojon, B. (2000) "Financial structure and the interest rate channel of ECB monetary policy," ECB Working Paper Series, No. 40.

Obstfeld, M. and Rogoff, K. (2000) "New directions for stochastic open economy models," Journal of International Economics, 50, 117-153. 
Peersman, G. and Smets, F. (2001) "The monetary transmission mechanism in the euro area: more evidence from VAR analysis," ECB Working Paper Series, No. 91.

Ricci, L. A. (2008) “A model of an optimum currency area," Economics: The Open-Access, Open-Assessment E-Journal, 2, 1-31.

Zhang, Z., Sato, K. and McAleer, M. (2004) "Asian monetary integration: a structural VAR approach," Mathematics and Computers in Simulation, 64, 447-458.

Zimmermann, K. F. (2009) "Labor mobility and the integration of European labor markets," IZA Discussion Paper Series, No. 3999. 